\title{
O DESAFIO MUNICIPAL DE INSERÇÃO DA MEDICINA INTEGRATIVA NA SAÚDE PÚBLICA: UM OLHAR PARA AS PRÁTICAS DE STRATEGIZING E ORGANIZING
}

\author{
Vanessa Alves Pinhal ${ }^{2}$ \\ Jacquelaine Florindo Borges ${ }^{3}$
}

http://dx.doi.org/10.1590/1413-2311.234.87768

\section{RESUMO}

O Sistema Único de Saúde (SUS) passou a oferecer práticas da Medicina Integrativa (MI), desde a regulamentação da Política Nacional de Práticas Integrativas e Complementares, em 2006. Este artigo analisa os modos de configuração das práticas de strategizing e de organizing com a inserção da MI no sistema público de saúde, a partir dos estudos da estratégia como prática social. A pesquisa foi realizada em três unidades de atendimento, utilizando pesquisa documental, observação/caderno de campo e entrevistas. Os resultados mostram relações desequilibrada e interdependente das práticas de strategizing e organizing em um contexto de tensão relacional entre as práticas tradicionais e as práticas integrativas de saúde pública. A pesquisa contribui com o estudo sobre a mudança nas práticas organizacionais ao mostrar os praticantes fazendo uso de recursos conforme as regras, mas também criando alternativas,transformando as regras e desenvolvendo novos recursos.

Palavras-chave: Estratégia como prática. Organizing. Strategizing. Organizações pluralísticas. Mudança organizacional.

\footnotetext{
${ }^{1}$ Recebido em 30/10/2018; aprovado em 03/04/2019.

${ }^{2}$ Universidade Federal de Uberlândia - Faculdade de Gestão e Negócios da Universidade Federal de Uberlândia - FAGEN/UFU; Uberlândia - MG (Brasil) - vanessa-pinhal@hotmail.com

${ }^{3}$ Universidade Federal de Uberlândia - Faculdade de Gestão e Negócios da Universidade Federal de Uberlândia - FAGEN/UFU; Uberlândia - MG (Brasil) - jacborges@ufu.br
} 


\title{
THE MUNICIPAL CHALLENGE OF THE INSERTION OF INTEGRATIVE MEDICINE IN PUBLIC HEALTH: A LOOK AT THE STRATEGIZING AND ORGANIZING PRACTICES
}

\begin{abstract}
The Unified Health System (SUS) started to offer Integrative Medicine (IM) practices since the regulation of National Policy on Integrative and Complementary Practices, in 2006. Thisstudy analyses the modes of association between strategizing and organizing with the insertion of IM in the public health system, from the perspective of studies about strategy as practice. The research was performed in three service units, using documentary research, observation/field notes and interviews. The results show unbalanced and interdependent relations between strategizing and organizing practices in a context of relational tension between traditional practices and integrative practices in public health. The research contributes with studies about changes in organizational practices by showing practitioners making use of resources according to the rules, but also by creating alternatives, transforming rules, and developing new resources.
\end{abstract}

Keywords: Strategy as practice. Organizing. Strategizing. Pluralistic organizations. Organizational changes.

\section{EL DESAFÍO MUNICIPAL DE INSERCIÓN DE LA MEDICINA INTEGRADORA EN SALUD PÚBLICA: UNA MIRADA A LAS PRÁCTICAS DE STRATEGIZING Y ORGANIZING}

\section{RESUMEN}

El Sistema Único de Salud (SUS) pasó a ofrecer prácticas de la Medicina Integradora (MI), desde la reglamentación de la Política Nacional de Prácticas Integrativas y Complementarias, en 2006. Este artículo analiza los modos de configuración de las prácticas de strategizing y de organizing com la inserción de la MI em el sistema público de salud, a partir de los estudios de la estrategia como práctica social. La investigación se realizo entres unidades de atención, utilizando investigación documental, observación/cuaderno de campo y entrevistas. Los resultados muestran relaciones desequilibradas e interdependientes entre las prácticas de 
strategizing y de organizing en un contexto de tensión relacional entre las prácticas tradicionales y las prácticas integradoras de salud pública. La investigación contribuye com el estudio sobre cambio em las prácticas organizacionales al mostrar a los practicantes haciendo uso de recursos conforme a las reglas, pero también creando alternativas, transformando las reglas y desarrollando nuevos recursos.

Palabras clave: Estrategia como práctica. Organizing. Strategizing. Organizaciones pluralistas. Cambio organizacional.

\section{INTRODUÇÃO}

No Brasil, a história da saúde pública foi marcada pelos conceitos de filantropia e caridade, enquanto o Estado desempenhava um papel limitado. Esse cenário mudou no início do século XX, quando os esforços do governo brasileiro com relação à saúde pública se intensificaram (CARVALHO, 2013; FINKELMAN, 2002). Outra mudança ocorreu no final da década de 1980, com a garantia do direito à saúde pela Constituição Federal de 1988, e posteriormente, na década de 1990, com a institucionalização do Sistema Único de Saúde (SUS) (NORONHA; LIMA; MACHADO, 2008). Nos anos 2000, intensificaram-se os anseios da sociedade por um sistema de saúde que contemplasse toda a população de maneira igualitária e, o desejo por práticas alternativas no atendimento à saúde (RAKEL, 2012).

Em 2006, com o apoio da Organização Mundial da Saúde (OMS), foi implantada a Política Nacional de Práticas Integrativas e Complementares (PNPIC), que proporciona aos usuários do SUS o acesso às práticas integrativas. Essa política visa atender, sobretudo, a necessidade de se conhecer e regulamentar experiências relativas às práticas integrativas, as quais já vinham sendo oferecidas na rede pública de muitos municípios (BRASIL, 2009). As práticas da PNPIC são incorporadas pela abordagem da Medicina Integrativa (MI), que tem o foco na cura e não na doença, e enfatiza os aspectos emocionais e psicológicos no tratamento (RAKEL, 2012).

A administração pública da saúde tem sido influenciada pelo modelo da Nova Gestão Pública (NGP), desde meados de 1995, o qual é dirigido para a busca de resultados, a melhoria do desempenho e da governança (metas, indicadores, transparência, maior controle por parte dos cidadãos) e flexibilização burocrática, ao incluir uma pluralidade de provedores, incluindo entidades da sociedade civil (SANO; ABRUCIO, 2008; REZENDE, 2009). Este modelo de gestão é promovido em um período de crise do Estado e ascensão do 
gerencialismo (PAULA, 2007). Ao mesmo tempo, tem-se a busca por superação de dicotomias e a pressão da população por serviços e práticas no campo da saúde (ESCOREL; AROUCA, 2016).

Considerando este cenário, a presente pesquisa ${ }^{4}$ busca responder a seguinte questão: como se configuram as práticas de strategizing e de organizing com a inserção da MI no sistema público de saúde, a partir da perspectiva da estratégia como prática social? O objetivo é analisar a configuração dessas práticas em unidades de saúde que as oferecem. Para a fundamentação teórica foram utilizados estudos da estratégia como prática (ECP), os conceitos de estruturação e campo oriundos da sociologia e estudos sobre a MI. A partir de pressupostos interpretativistas e de uma abordagem qualitativa, coletou-se os dados em três unidades municipais de saúde. Os estudos da estratégia vistos como uma prática social valorizam as ações e os papéis dos estrategistas, assim como as inter-relações entre as práticas do micro e do macro contexto (WHITTINGTON, 2004), e as configurações entre strategizing e organizing em contextos pluralísticos (JARZABKOWSKI; FENTON, 2006).

Este artigo está estruturado em seis seções, incluindo esta introdução. O referencial teórico é apresentado nas três seções seguintes, respectivamente, conceitos de strategizing e organizing na perspectiva da ECP; a mudança e criação de novas práticas e a Medicina Integrativa e diferentes concepções de saúde pública. Os procedimentos metodológicos são apresentados em seção específica, seguidos dos resultados e conclusões.

\section{PRÁticas de Strategizing E organizing NA PERSPECTIVA DA ESTRATÉGIA COMO UMA PRÁTICA SOCIAL}

A perspectiva da ECP tem o foco nos praticantes da estratégia e em suas práticas com ênfase nas inter-relações entre os níveis macro e micro (JARZABKOWSKI, 2004; WHITTINGTON, 2004). A ênfase está nas atividades organizacionais cotidianas dos atores envolvidos com a estratégia (JOHNSON et al, 2003) e na maneira como esses indivíduos administram-nas no cotidiano organizacional (WHITTINGTON, 2003). A estratégia é entendida como uma atividade situada e socialmente construída por meio das ações e interações de múltiplos atores (JARZABKOWSKI, 2005). A estratégia é uma prática social, em que as micro ações são microfenômenos que precisam ser compreendidos em seu contexto social mais amplo, a partir da interação dos atores (JARZABKOWSKI;

\footnotetext{
${ }^{4}$ Esta pesquisa foi realizada com o suporte de uma bolsa da Coordenação de Aperfeiçoamento de Pessoal de Nível Superior - Brasil (CAPES).
} 
BALOGUN; SEIDL, 2007). Dentre as práticas estudadas, estão as práticas de organizing e strategizing, abordadas por diversos autores (COLVILLE; MURPHY, 2006; JARZABKOWSKI; FENTON，2006; RIVKIN; SIGGELKOW，2006; WHITTINGTON, 2003; WHITTINGTON; MELIN, 2003; WHITTINGTON et al., 2006).

A pluralidade é uma das características da ECP, especialmente a pluralidade dos níveis de análise (individual, organizacional e institucional, e suas relações); a pluralidade dos atores com a inclusão de outros profissionais (internos e externos) nas análises, além dos executivos de alto escalão; e a pluralidade do contexto em que as práticas se desenvolvem (JARZABKOWSKI; FENTON, 2006). Contextos pluralísticos são caracterizados por diversos objetivos e interesses de diferentes grupos, de dentro e de fora da organização (JARZABKOWSKI; FENTON, 2006), por "múltiplos objetivos, por poder difuso e por processos de trabalho baseados no conhecimento" (DENIS; LANGLEY; ROULEAU, 2007, p. 179).

Esta pluralidade tem implicações, visto que ela produz tensão relacional (WILSON; JARZABKOWSKI, 2004). Conforme Jarzabkowski e Fenton (2006) essas tensões relacionais são produzidas nas interações cotidianas e geram diferentes configurações das práticas de strategizing e organizing. Esses autores relacionam as práticas de strategizing com planejamento, alocação de recursos e práticas de monitoramento pelos quais a estratégia é estabelecida, e as práticas de organizing com a criação de estruturas e processos de coordenação pelos atores internos da organização, para que se estabeleça a identidade, a cultura e os interesses da empresa.

Os autores identificam três modos de associação entre organizing e strategizing: (A) interdependente, (B) destrutivo, (C) desequilibrado. No modo de associação interdependente (A), strategizing e organizing são mutuamente reforçados, as práticas de organizing são adaptadas às demandas de diferentes objetivos estratégicos e as práticas de strategizing. A associação destrutiva (B) ocorre devido ao extremo pluralismo em ambos os domínios. Quando múltiplos objetivos estratégicos não podem ser alinhados ou estão em conflito com os objetivos estratégicos, a organização é pressionada em muitas direções para solucionar as múltiplas demandas, requerendo maiores mudanças ou levando a um colapso organizacional. No modo desequilibrado (C), os objetivos estratégicos estão bloqueados por práticas de organizing, que desviam a atenção de determinados objetivos para outros, enquanto as práticas de strategizing enfatizam os interesses de algumas partes da organização em detrimento de outras. No sub modo (A), os processos e as práticas pluralísticos de organizing agem como bloqueadores às tentativas de implementação de novas estratégias. No sub modo 
(B), múltiplas demandas estratégicas não podem ser acomodadas devido à singularidade dos processos de organizing.

Esses modos de configuração decorrem de três princípios sobre o tipo de gerenciamento das associações entre strategizing e organizing, em vista da pluralidade que caracteriza a prática estratégica (JARZABKOWSKI; FENTON, 2006): (1) as organizações não podem ser submetidas a um ritmo de períodos estáveis pontuados por períodos de mudança, mas devem ajustar-se continuamente às novas exigências; (2) as organizações devem manter-se independentes, abordando os vários pequenos desequilíbrios e fazendo ajustes mútuos continuamente; e, (3) o diálogo constante entre a alta administração e seus constituintes é necessário, possibilitando consenso para resolvê-los.

O conceito de contextos organizacionais pluralísticos pode ser aplicado em qualquer lugar, conforme Denis, Langley e Rouleau (2007), entretanto existem organizações que demonstram ser "mais pluralísticas" do que outras, como por exemplo, os hospitais, organizações de arte e universidades. Para esses autores, o strategizing pode ser visto como a criação de redes baseadas em valores e constituídas a partir/através de rotinas. Em contextos pluralísticos, os estrategistas devem ver a si mesmos como mergulhados em um processo contínuo de troca com os outros atores, e não como uma autoridade externa que impõe estratégias.

\section{MUDANÇAS E CRIAÇÃO DE NOVAS PRÁTICAS NA PERSPECTIVA DA ECP E DOS ESTUDOS BASEADOS NA PRÁTICA (PRACTICE-BASED STUDIES - PBS)}

As organizações não são consideradas entidades fixas na abordagem da ECP, porém Jarzabkowski (2004) relata que as rotinas estratégicas e operacionais de uma organização possuem propriedades que a predispõem a atuar de determinadas maneiras, e mais importante, definem as possíveis decisões a serem tomadas. Essas rotinas são socialmente complexas, incorporadas e interligadas, de modo que elas compreendem uma arquitetura social que penetra nos canais de comunicação, nos filtros de informação, e nas estratégias de resolução de problemas, fazendo com que se torne mais difícil para que essa organização absorva novas maneiras de fazer as coisas (como, por exemplo, a incorporação de tecnologias).

A aceleração das mudanças nos ambientes de atuação das organizações promove maior atenção às habilidades práticas. Whittington et al. (2006) cita três mudanças de foco ao considerar a abordagem da prática e essa condição de transformação dos ambientes de 
atuação: (a) de "estados" para "atividades" - as estratégias e organizações estão constantemente sendo feitas e refeitas, e se tornam reconcebidas como atividades contínuas do strategizing e organizing e não como estados dos mesmos; (b) de "analítico" para "prático" - essas atividades não são meramente analíticas, como na tradicional sequência da formulação para a implantação, mas o são intensamente práticas, frequentemente em formas de rotinas; (c) do "dualismo" para "dualidade" - a organização e a estratégia não são vistas como variáveis separadas, mas acontecem juntas como atividades simultâneas. Além disso, as duas são interdependentes, já que o organizing molda parcialmente o strategizing. Essa dualidade implica em barreiras não tão definidas em que o strategizing e organizing se tornam similares. A dualidade strategizing/organizing resgata a estratégia de seu pedestal, e a coloca novamente na realidade complexa e desordenada da organização.

As mudanças são inerentes aos contextos pluralísticos, visto que a pluralidade de praticantes atuando em variados níveis (micro-macro, individual-coletivo) possuem objetivos diversos, conforme os diferentes grupos presentes dentro e fora da organização (JARZABKOWSKI; FENTON, 2006). Nicolini (2009) afirma que é importante que ocorra uma integração e um movimento alternado entre uma visão ampla e outra mais restrita no estudo das práticas. Essas combinações entre níveis possibilitam uma melhor compreensão a respeito de como as práticas locais participam nas grandes configurações e como elas entram com seus elementos e recursos em outras atividades. As práticas locais são aquelas identificadas em determinado contexto específico que está sendo analisado, como as práticas da telemedicina, estudada por esse autor.

Os Estudos Baseados na Prática - EBP (Practice-Based Studies - PBS) se interessam pela relação entre a aprendizagem, o conhecimento e a tecnologia no espaço social (BISPO, 2013). Aprendizagem e conhecimento ocorrem através de constelações de práticas situadas e socialmente aprendidas e refinadas (GHERARDI; NICOLINI, 2002; GHERARDI, 2012). O interesse em novas práticas, dentre elas a telemedicina (GHERARDI, 2010; NICOLINI, 2012). As novas práticas ocorrem através de testes e experimentações, também exigem a negociação de elementos estéticos, provocam julgamentos éticos e instrumentais, trazem implicações para a construção de identidades e influencia performances (GHERARDI, 2009).

Em estudo sobre a consulta telecardiológica, ou seja, consulta médica à distância com um cardiologista, Gherardi (2010) analisou as práticas discursivas envolvidas em um mês de consultas, a fim de entender os efeitos dessa nova prática em um contexto de cuidados de saúde ocidental. A autora sugere que as tecnologias usadas (sistemas telefônicos, tecnologias de informação) não nascem "utilizáveis" ou "confiáveis" de maneira independente dos 
usuários, pelo contrário, se tornam assim quando seu uso as institucionaliza como uma "prática" dentre tantas outras existentes. As consultas telecardiológicas são consideradas uma prática material-semiótica, em que as expertises social e material são combinadas para realizar uma nova forma de serviço de saúde que seja confiável.

Em estudo sobre a reconfiguração das práticas no campo da telemedicina, que proporciona consultas à distância por meio de ligações telefônicas, a partir de uma estrutura tecnológica adequada, Nicolini (2007) utilizou os conceitos de "alongamento" (quando existe pressão sobre as práticas médicas atuais, que se tornam inapropriadas para as condições de trabalho) e "expansão" (redistribuição, reconfiguração de atividades existentes) para explorar o que acontece quando as práticas médicas são reconfiguradas espacial e temporalmente. Com a utilização dos princípios da teoria prática contemporânea e com a realização de um estudo longitudinal de três anos na Itália, o autor investiga questões relacionadas à prática geradas pela subversão dos princípios de proximidade que ainda caracteriza a prática médica. Os resultados do estudo mostram que, para lidar com a expansão de seu trabalho, os praticantes tiveram que enfrentar três problemas principais: (1) redistribuir seu trabalho entre elementos humanos e não humanos; (2) reformular o modo como às atividades eram feitas; e, (3) reconfigurar a relação entre todos os envolvidos no processo. Este estudo mostrou que essa reconfiguração provoca mudanças mais profundas, incluindo a reformulação do objeto e conteúdo da atividade, o surgimento de novas identidades e a modificação de relações de poder dos envolvidos.

Ainda na área médica, Maniatopoulos et al. (2015) realizaram um estudo de caso de três anos no Serviço Nacional de Saúde da Inglaterra, baseado na noção de "campo de práticas" (field of practices) de Theodore Schatzki. No estudo, os autores analisaram como as inovações tecnológicas são adotadas e incorporadas nas práticas de saúde, especificamente o Breas Lymph Node Assay que é uma nova tecnologia de diagnóstico para o tratamento do câncer de mama. Os resultados do estudo mostram uma visão integrada da adoção da tecnologia, em que o sucesso depende de como as organizações, usuários e tecnologias são configurados em ordens sociais, culturais e materiais, estando todos interligados entre si. Com isso, é reforçada a importância de se considerar o contexto mais amplo em que a adoção de tecnologias acontece, isto é, ir além dos limites da prática local e trabalhar com uma perspectiva que considere o campo dessas práticas inter-relacionadas. O estudo consegue mostrar as reconfigurações tecnológicas por meio de experiências de diversas partes interessadas incluindo médicos, gestores e outros especialistas, fornecendo uma compreensão 
a partir de perspectivas diferentes e revelando os fatores profissionais, organizacionais e sociais que influenciam e moldam o processo de adoção da tecnologia.

\section{A MEDICINA INTEGRATIVA E DIFERENTES CONCEPÇÕES DE SAÚdE PÚBLICA}

Em 1920, a saúde pública era tratada como a "ciência e a arte de evitar a doença" (BUSS, 2009, p. 23). A definição para o termo "saúde pública" é controversa devido ao próprio conceito de saúde, que conforme a OMS (OMS, 1948) é "[...] o estado do mais completo bem-estar físico, mental e social e não apenas a ausência de doença ou enfermidade". Esse conceito sofreu críticas por sua amplitude e pela ideia da saúde como algo utópico (SCLIAR, 2007; SEGRE; FERRAZ, 1997).

As relações entre a saúde e as condições de vida das pessoas começaram a ser discutidas na própria origem da medicina moderna. O processo de industrialização ocorrido na Europa, principalmente entre o final do século XVIII e início do século XIX, fez com que fossem alteradas as condições de vida e de trabalho nas cidades quando acompanhada por uma elevação na ocorrência de epidemias (CASTRO et al, 2010). Diante desse contexto, as doenças começaram a ser relacionadas às condições de existência dos indivíduos. $\mathrm{O}$ conhecimento científico acerca das condições de saúde da população encontrava expressão no estudo da higiene, ou seja, o estudo do homem e dos animais e sua relação com o meio (MINAYO; COIMBRA JR., 2005).

$\mathrm{Na}$ época, duas visões sobre a causa e a forma de transmissão de doenças eram discutidas: a contagionista e a anticontagionista (ou infeccionista). A primeira defendia que a doença era um desequilíbrio relacionado ao conjunto de circunstâncias que interferem na vida de uma pessoa, constituindo uma predisposição favorável ao aparecimento de doenças. Como resultado dessa concepção, destaca-se o isolamento de doentes, a desinfecção de objetos e a instituição de quarentenas. Já a segunda concepção defendia o contrário, que era necessário identificar uma causa específica que originava a doença, era defendido o conceito de infecção como base explicativa ao processo de adoecimento (CASTRO et al, 2010; MINAYO; COIMBRA JR., 2005).

A perspectiva contagionista ganhou força entre os estudiosos, fazendo com que as doenças fossem compreendidas como a relação entre um agente etiológico (causador de uma doença, como um vírus ou bactéria, por exemplo), alterações fisiopatológicas e os sintomas. Com isso, o sujeito portador da doença e seu ambiente passaram para um plano secundário, 
fazendo com que o foco do médico fosse à doença, e não no paciente (CASTRO et al, 2010). Entretanto, esse conflito envolvendo aqueles que defendiam causas e intervenções gerais contrapondo-se àqueles que buscavam sanar causas específicas das doenças continuou existindo na medicina.

Entre 1920 e 1950 surge um contexto de críticas à medicina curativa - relacionada à visão contagionista - fazendo emergir um movimento voltado para a medicina preventiva, principalmente em países como Estados Unidos, Inglaterra e Canadá (CASTRO et al, 2010). A partir de 1960 (AROUCA, 2003; ESCRIVÃO JUNIOR, 2012), a Medicina Preventiva emerge como uma reação à ideologia curativa da prática médica vigente, à especialização crescente da medicina, ao conhecimento médico predominantemente biológico e ao domínio da ideologia curativa no ensino/educação (AROUCA, 2003).

Considerando a saúde pública nesse contexto, é possível identificar pelo menos três padrões de pensamento no campo, construídos ao longo do tempo. O primeiro padrão referese à saúde pública tradicional e caracteriza-se por um modelo teórico clínico, biomédico. $\mathrm{O}$ homem é o objeto de uma ação sanitária, sendo submetido a ações técnico-normativas da saúde pública, determinada pelos parâmetros técnicos definidos pelos profissionais de saúde. A saúde pública submetia todos às suas prescrições, pautada na positividade e autoridade técnica. O segundo padrão é resultado da influência do pensamento social, sobretudo em sua vertente histórico-estruturalista sobre o pensamento biomédico, constituindo propriamente o campo da saúde coletiva. É aqui que a saúde pública incorpora o social e ganha força política, aproximando-se das ideias de democracia e equidade. Finalmente, o terceiro padrão reconhece que a saúde pública é subjetiva e de vocação antipositivista, acreditando que o modelo biomédico é ineficaz e enganador (CARVALHO, 1996; OLIVEIRA, 2000).

As transformações nesta área também envolvem uma mudança em direção ao conceito de promoção da saúde: disponibilizar meios e fazer com que as pessoas exerçam maior controle sobre sua saúde (FINKELMAN, 2002). O termo "promoção da saúde" foi usado pela primeira vez por Sigerist, historiador da medicina, em 1945, quando ele definiu quatro funções da medicina: promoção da saúde, prevenção da doença, restauração do doente e reabilitação (CASTRO et al, 2010).

A Medicina Integrativa é outro conceito difundido na área médica que também vai ao encontro da promoção da saúde e da prevenção da doença, destacando ações como atividade física, exames de prevenção, nutrição e gerenciamento do estresse (MAIZES, 1999). Essa abordagem é orientada para a cura, enfatizando a centralidade médico-paciente. O foco está nos métodos menos invasivos e menos custosos, sendo o seu intuito integrar as terapias 
tradicionais (da medicina curativa) com as complementares (baseadas nos aspectos emocional, psicológico e espiritual do indivíduo) (RAKEL, 2012).

As funções presentes na definição do termo "promoção da saúde" voltam a remeter à própria Medicina Preventiva, abordada por Arouca (2003), no que ele intitulou de "dilema preventivista" (AROUCA, 2003). Com o intuito de retomar essa discussão e refletir sobre sua atualização, Costa, Misoczky e Abdala (2018) tomam como base a tese de Arouca para fazer as articulações entre o movimento de promoção à saúde e o dilema preventivista.

Os autores identificaram o dilema promocionista, que se aproxima do dilema preventivista. Nesse sentido, não há rompimento com a contradição fundamental da medicina, apresentada por Arouca, mas sim uma atualização do discurso da medicina preventiva. Na atualização, a promoção da saúde transforma a saúde (valor de uso), em valor de troca, mediado por relações sociais subordinadas à lógica do mercado uma vez que o enfoque dos cuidados sob a responsabilidade do indivíduo aprofunda essa contradição, na medida em que as pessoas são convertidas em empresárias de si mesmas (COSTA; MISOCZKY; ABDALA, 2018).

O governo brasileiro começou a considerar a saúde como prioridade no começo do século XX (Figura 1), com a implantação da economia exportadora de café, no Sudeste do país. A melhoria das condições sanitárias, entendida então como dependente basicamente do controle das endemias e do saneamento dos portos e do meio urbano, tornou-se uma efetiva política de Estado. A partir de então, a saúde passou a fazer parte de políticas e debates sobre o tema, realizados no país.

A PNPIC reconhece que as "novas" terapias da MI nas unidades de saúde contribuem para a ampliação da corresponsabilidade dos indivíduos pela saúde, ampliando o exercício da cidadania (BRASIL, 2006). Após a institucionalização da PNPIC, ocorreram as regulamentações estaduais e municipais, conforme Resolução de aprovação das PIC em Minas Gerais e a Lei n. 11.309 de 18 de fevereiro de 2013 e o Decreto n. 14.597 de 27 de dezembro de 2013 sobre as PIC em Uberlândia (UBERLÂNDIA, 2013a, 2013b).

A relevância da MI no contexto da saúde pública tem sido objeto de estudos, desde 2006, com investigações sobre o interesse e aceitação dos profissionais de saúde das práticas integrativas (MACHADO; CZERMAINSKI; LOPES, 2012; NAGAI; QUEIROZ, 2011; ISCHKANIAN; PELICIONI, 2012), conhecimento das práticas tanto por profissionais quanto por usuários (FONTANELLA et al., 2007; LIMA; SILVA; TESSER, 2014; LOCHNECKEL; CARMIGNAN; CREPALDI, 2010; PEREIRA; VILLELA, 2008; WHO, 2013) e 
identificação de potenciais e desafios do trabalho interprofissional com as PIC (BARROS; SPADACIO; COSTA, 2018).

\section{Figura 1 - Síntese das transformações do quadro sanitário brasileiro}

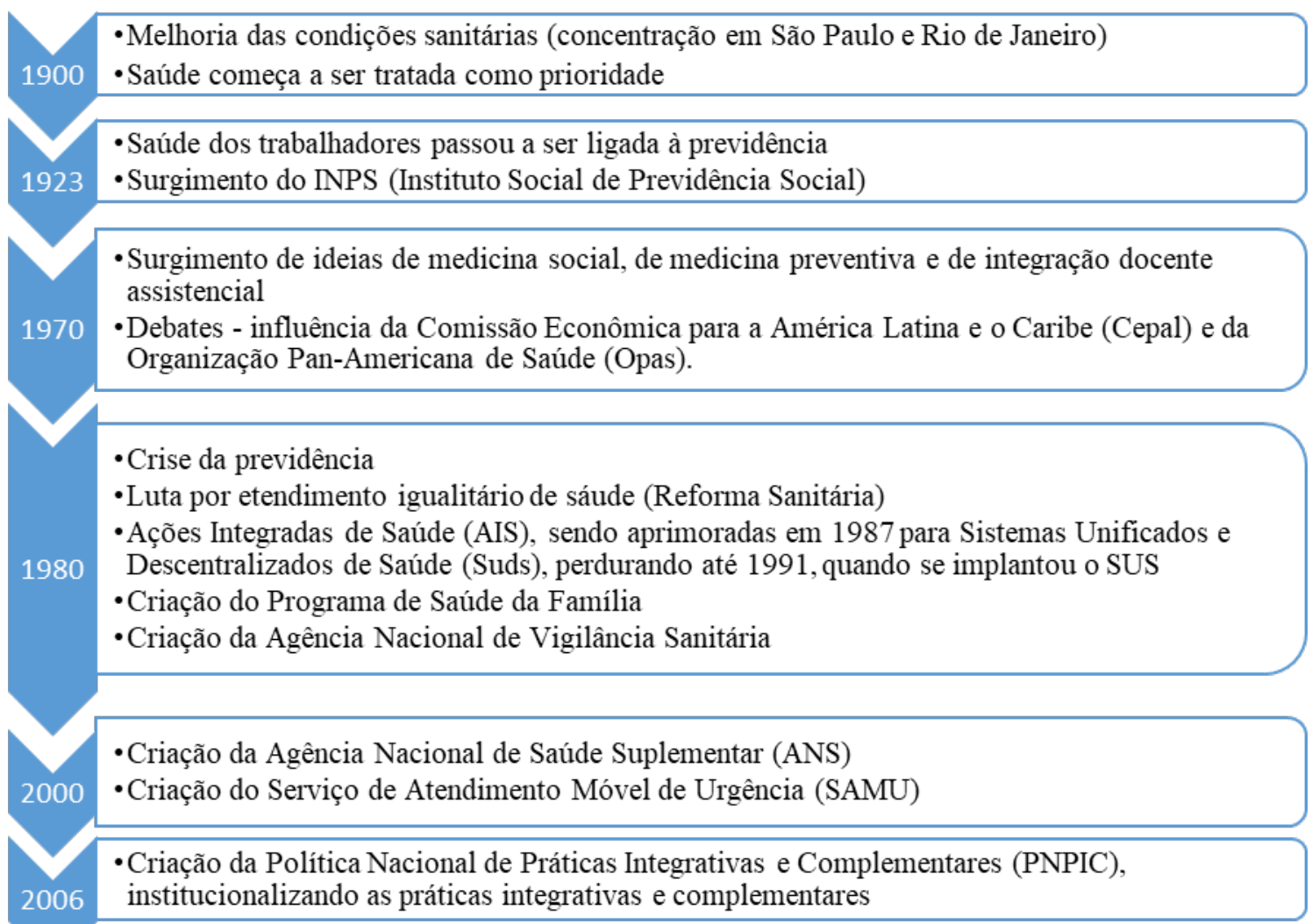

Fonte: elaborada pelas autoras com base em Carvalho (2013), Finkelman (2002), Paim et. al (2011) e Vecina Neto (2016).

Ao estudarem a situação das PIC na Atenção Primária à Saúde no Brasil, Tesser, Souza e Nascimento (2018) mostraram que houve uma pequena expansão na oferta das PIC, que há pouca regulamentação nacional no que tange à formação e prática em relação às PIC, que a inserção do tema no ensino ainda é incipiente e a maioria dos praticantes são profissionais com visão convencional da Atenção Primária, que desempenham papel de destaque na expansão. A PNPIC implica práticas menos ortodoxas de tratamento (MI), incluindo uma nova concepção da relação médico-paciente, do papel de aspectos emocionais, psicológicos e espirituais nos tratamentos, do estreitamento de relações sociopolíticas com a ampliação do papel do cidadão.

Tais práticas de saúde pública vêm sendo implantadas em um cenário de gestão pública em que se identifica uma forte presença da ideologia gerencialista (PAULA, 2008); frequentes questionamentos sobre a eficiência na alocação de recursos no campo do 
atendimento público de saúde (MENDES; LEITE; MARQUES, 2011; SANTOS; FRANCISCO; GONÇALVES, 2016); adoção de diferentes concepções sobre governança e adoção de parcerias público-privadas (PECI; PIERANTI; RODRIGUES, 2008); busca por mais agilidade das decisões ao mesmo tempo em que se enfrentam problemas oriundos de uma alta rotatividade dos gestores, devido a processos partidários/eleitorais que geram descontinuidade, permanentes recomeços e insatisfação dos profissionais (LORENZETTI et al., 2014); precariedade na informatização e digitalização das informações e dos processos (FERNANDES; MACHADO;ANSCHAU, 2009); a necessidade de ampliação dos canais de comunicação para o avanço da participação da população nas políticas públicas de saúde (ESCOREL; AROUCA, 2016) .

O cenário da gestão pública no campo da saúde gera tensão relacionada com este movimento de "reinvenção do governo", nas últimas décadas, a partir do culto ao gerencialismo e ao management (culto ao sucesso, empreendedorismo e inovação e crença nos poderes da tecnologia e racionalização de processos), o qual pode comprometer a dimensão sociopolítica da gestão pública, em prol da dimensão financeira e da produtividade econômica (LODGE; GILL, 2011; PAULA, 2007) e dificultar a superação de dicotomias (saber popular versus saber técnico, participação sem mediação política versus participação institucionalizada, participação direta versus participação indireta) e uma maior participação da população em políticas públicas com a promoção de cidadania/democracia/saúde.

\section{PROCEDIMENTOS METODOLÓGICOS}

Esta pesquisa baseia-se nos pressupostos interpretativistas da ECP (GRIX, 2002; VAARA; WHITTINGTON, 2012) e adota a abordagem qualitativa (DENZIN; LINCOLN, 2005). O Quadro 1 sintetiza o percurso da pesquisa e as categorias de análise que orientaram a coleta de dados no campo. A partir do referencial teórico, foram identificados os elementos de um contexto organizacional pluralístico, conforme Jarzabkowski e Fenton (2006) e Denis, Langley e Rouleau (2007). Estes últimos citam os hospitais como exemplos de organizações com contextos pluralísticos. Nesta pesquisa, o foco são as Unidades Municipais de Saúde que oferecem práticas de MI, além das práticas da Medicina Convencional. A partir do estudo de Jarzabkowski e Fenton (2006) sobre os modos de associação entre as práticas de strategizing e organizing e da revisão teórica sobre MI, foram definidas as categorias de análise da pesquisa. 
Quadro 1 - Percurso da pesquisa

\begin{tabular}{|c|c|c|c|}
\hline \multirow{2}{*}{$\begin{array}{c}\text { Contexto Organizacional } \\
\text { Pluralístico }\end{array}$} & \multicolumn{2}{|c|}{ Categorias de análise } & \multirow{2}{*}{$\begin{array}{c}\text { Resultados da } \\
\text { análise: modos } \\
\text { de associação } \\
\text { entre } \\
\text { Organizing e } \\
\text { Strategizing }\end{array}$} \\
\hline & Organizing & Strategizing & \\
\hline $\begin{array}{l}\text { - Foco da saúde pública: } \\
\text { do "individual" para o } \\
\text { "coletivo" e da } \\
\text { "prevenção" para a } \\
\text { "promoção" } \\
\text { - A sociedade passa a } \\
\text { debater a importância da } \\
\text { qualidade de vida e hábitos } \\
\text { saudáveis. } \\
\text { - Interesse social por } \\
\text { práticas alternativas de } \\
\text { saúde menos invasivas e } \\
\text { menos custosas. } \\
\text { - Dicotomia entre o amplo } \\
\text { e integral (Medicina } \\
\text { Integrativa) e } \\
\text { especialidade e } \\
\text { conhecimento fragmentado } \\
\text { (Medicina Convencional). }\end{array}$ & $\begin{array}{l}\text { - Valores relacionados com a } \\
\text { MI: alterações/ permanência } \\
\text { de comportamentos/ } \\
\text { interesses entre os atores } \\
\text { com a inserção das PIC. } \\
\text { - Imagens ou formas de } \\
\text { representar a MI pelos } \\
\text { públicos pesquisados } \\
\text { - Reconfiguração da relação } \\
\text { entre todos os envolvidos } \\
\text { para acomodar os interesses } \\
\text { dos atores estratégicos com } \\
\text { a inserção das práticas da } \\
\text { MI. } \\
\text { - Formas de interação/diálogo } \\
\text { entre os diversos atores } \\
\text { estratégicos sobre como } \\
\text { conduzir as práticas da MI } \\
\text { na Unidade de saúde. } \\
\text { - Práticas de disseminação/ } \\
\text { comunicação da MI entre os } \\
\text { atores estratégicos }\end{array}$ & $\begin{array}{l}\text { - Objetivos: interesses e } \\
\text { expectativas com a } \\
\text { inserção da MI no } \\
\text { atendimento público de } \\
\text { saúde. } \\
\text { - Destinação de recursos } \\
\text { para MI vis a vis a MT. } \\
\text { - As mudanças na unidade } \\
\text { de saúde para viabilizar a } \\
\text { oferta da MI. } \\
\text { - Tensão: consensos e } \\
\text { divergências a respeito } \\
\text { dos resultados da } \\
\text { inserção das novas } \\
\text { práticas de MI. } \\
\text { - Tensão: consensos e } \\
\text { divergências a respeito } \\
\text { do futuro da MI no } \\
\text { atendimento público de } \\
\text { saúde }\end{array}$ & Interdependente \\
\hline
\end{tabular}

Fonte: elaborado pelas autoras.

A coleta dos dados foi realizada por meio de pesquisa documental (RICHARDSON, 2014), observação não participante (Quadro 2) e notas de caderno de campo (STAKE, 1994) e entrevistas semiestruturadas (Quadro 3) (PATTON, 1990). O método de procedimento utilizado foi a pesquisa de campo, conduzida no município de Uberlândia/MG, que possui um total de 61 estabelecimentos de saúde, onde sete (7) oferecem as PIC. Dentre os sete (7), três (3) foram selecionados para este estudo, utilizando-se os seguintes critérios: uma unidade pioneira no oferecimento das PIC em Uberlândia (Unidade Alecrim); uma unidade que oferece apenas atendimentos nos serviços das PIC (Unidade Malva), se diferenciando de todas as outras; e uma unidade escolhida pela facilidade de contato no agendamento da entrevista com a coordenação (Unidade Camomila). 


\section{Quadro 2 - Atividades da observação direta}

\begin{tabular}{|l|l|l|}
\hline \multicolumn{1}{|c|}{ Atividade } & \multicolumn{1}{|c|}{ Tempo de Observação } & \multicolumn{1}{c|}{ Pontos observados nas três unidades analisadas } \\
\hline Reuniões & 4horas & $\begin{array}{l}\text { Assuntos mais frequentes; avaliações informais sobre o } \\
\text { futuro relacionado às PIC; formas de interações. }\end{array}$ \\
\hline $\begin{array}{l}\text { Audiência Pública } \\
\text { sobre Plantas } \\
\text { Medicinais }\end{array}$ & 3 horas & $\begin{array}{l}\text { Assuntos mais frequentes; avaliações informais sobre o } \\
\text { futuro relacionado às PIC; formas de interações; } \\
\text { público envolvido. }\end{array}$ \\
\hline Salas de Espera & 30 horas e 30 minutos & $\begin{array}{l}\text { Relações entre usuários e os profissionais; } \\
\text { infraestrutura e recursos; comentários/avaliações } \\
\text { emitidas de forma espontânea pelos usuários. }\end{array}$ \\
\hline Tempo total & 37 horas e 30 minutos & \multicolumn{2}{|c}{} \\
\hline
\end{tabular}

Fonte: dados da pesquisa.

Quadro 3 - Características e quantidade de profissionais entrevistados

\begin{tabular}{|c|c|c|c|c|}
\hline $\begin{array}{c}\text { Identificação } \\
\text { (nomes } \\
\text { fictícios) }\end{array}$ & Atuação & Formação & $\begin{array}{c}\text { Tempo de } \\
\text { atuação no } \\
\text { setor público }\end{array}$ & Local de atuação \\
\hline João & Coordenação & $\begin{array}{l}\text { Segundo grau } \\
\text { Incompleto }\end{array}$ & 3,5 anos & Secretaria de Saúde \\
\hline Simone & $\begin{array}{l}\text { Coordenação e } \\
\text { Auriculoterapia }\end{array}$ & Enfermeira & 23 anos & $\begin{array}{l}\text { Unidade Malva e Unidade } \\
\text { Alecrim }\end{array}$ \\
\hline Vanda & Coordenação & $\begin{array}{l}\text { Assistente } \\
\text { Social }\end{array}$ & 12 anos & Unidade Alecrim \\
\hline Lenice & Coordenação & Enfermeira & 5 anos & Unidade Camomila \\
\hline Ana & Coordenação & Enfermeira & 5 anos & Unidade Camomila \\
\hline Jonas & Acupuntura & Medicina & 10 anos & Unidade Malva \\
\hline Denise & Acupuntura & Fisioterapia & 16 anos & Unidade Malva \\
\hline Tássia & Acupuntura & Fisioterapia & 13 anos & $\begin{array}{l}\text { Unidade Malva e Unidade } \\
\text { Camomila }\end{array}$ \\
\hline Carlos & Acupuntura & Biomedicina & 4 anos & Unidade Alecrim \\
\hline Elisa & Reiki & $\begin{array}{l}\text { Técnico em } \\
\text { Enfermagem }\end{array}$ & 33 anos & $\begin{array}{l}\text { Unidade Malva e Unidade } \\
\text { Alecrim }\end{array}$ \\
\hline Carla & $\begin{array}{l}\text { Terapia } \\
\text { Holística }\end{array}$ & $\begin{array}{l}\text { Técnico em } \\
\text { Enfermagem }\end{array}$ & 30 anos & Unidade Malva \\
\hline Vânia & $\begin{array}{l}\text { Medicina } \\
\text { Antroposófica }\end{array}$ & Medicina & $\begin{array}{l}2 \text { anos nessa } \\
\text { atividade }\end{array}$ & Unidade Malva \\
\hline Rodrigo & Homeopatia & Medicina & 10 anos & $\begin{array}{l}\text { Unidade Malva e Unidade } \\
\text { Alecrim }\end{array}$ \\
\hline Telma & Fitoterapia & Farmácia & 3 anos & Secretaria de Saúde \\
\hline Ângela & $\begin{array}{l}\text { Conselho Municipal de } \\
\text { Saúde }\end{array}$ & Psicóloga & $\begin{array}{l}\text { Membro do } \\
\text { Conselho há } 8 \\
\text { anos }\end{array}$ & Associação A \\
\hline Kátia & $\begin{array}{l}\text { Representa a Sociedade } \\
\text { Civil na Comissão } \\
\text { Consultiva PIC }\end{array}$ & Enfermeira & $\begin{array}{l}\text { Não é } \\
\text { funcionária } \\
\text { pública }\end{array}$ & Clínica Particular \\
\hline André & $\begin{array}{l}\text { Delegado local do } \\
\text { CRM de Uberlândia e } \\
\text { Corregedor do Estado }\end{array}$ & Médico & $\begin{array}{l}\text { Não é } \\
\text { funcionário } \\
\text { público }\end{array}$ & CRM em Uberlândia \\
\hline
\end{tabular}

Fonte: dados da pesquisa. 
A pesquisa foi conduzida naquelas unidades que oferecem o maior número de práticas de MI e em uma unidade que oferece apenas uma prática. Assim, seria possível conhecer as especificidades dessas unidades. O público entrevistado é composto por 17 profissionais (Quadro 3) e 51 entrevistas com usuários do sistema PIC. Dentre os profissionais, foram entrevistados coordenadores; profissionais da saúde que atuam com as PIC; uma representante do Conselho Municipal de Saúde; uma representante da Comissão Consultiva das PIC; e um representante do Conselho Regional de Medicina (CRM) de Uberlândia. As entrevistas com esses funcionários tiveram duração média de 30 minutos e foram gravadas com autorização de cada entrevistado. . Também foram realizadas 51 entrevistas com pacientes das terapias oferecidas nas unidades selecionadas, essas também foram gravadas e transcritas. O total de usuários atendidos em todas as unidades que oferecem as PIC em Uberlândia é de 1.490 (em setembro de 2016). Devido ao compromisso de confidencialidade, as unidades foram tratadas com nomes fictícios: unidade Camomila, inaugurada em 2012, oferece as PIC desde o início de suas atividades; Unidade Alecrim, fundada em 1982, iniciou a oferta das PIC em 2015; a Unidade Malva foi inaugurada em 2016 e, desde então, oferece apenas os serviços das PIC, e recebe pacientes de todas as regiões da cidade, de unidades que não oferecem essas terapias.

Devido à diferença de envolvimento e posição hierárquica dos profissionais entrevistados e também as entrevistas com os usuários, foram utilizados quatro roteiros-guias para a realização das entrevistas semiestruturadas. Todas as entrevistas foram transcritas para a análise. Em relação aos usuários, as entrevistas ocorreram nas salas de espera das unidades de forma aleatória, respeitando a voluntariedade dos mesmos em participar da pesquisa. A pesquisa foi cadastrada e aprovada pelo Conselho de Ética do sistema Plataforma Brasil.

\section{PRÁTICAS INTEGRATIVAS: TENSÕES RELACIONAIS NO CONTEXTO PLURALÍSTICO DA SAÚDE PÚBLICA}

A pesquisa de campo mostra a existência de tensão relacional nas práticas cotidianas entre concepções de saúde preventiva e concepção biomédica tradicional, o que gera dificuldades para a implantação da MI, ainda que todos os profissionais entrevistados reconheçam a importância das duas abordagens e a necessidade de integração entre elas.

A Atenção Básica, ela avançou um pouco, mas precisa avançar mais,

é, e ela tem que funcionar da forma mesmo como está, de promoção, prevenção à saúde. Porque se a gente tem um maior investimento na 
atenção básica, a gente vai evitar de ter gastos maiores com internação, com UTI, com pessoas nas UAIs lá nos corredores e internadas (entrevista concedida por Vanda, coordenação, 2016).

As terapias complementares não vieram para tirar o atendimento dos médicos, ela veio para complementar. Não é você escolher entre um e outro, é tratar a pessoa como um todo. Trata causa, não consequência (entrevista concedida por Kátia, comissão consultiva PIC, 2016).

Figura 2 - O contexto organizacional pluralístico de inserção das PIC na saúde pública

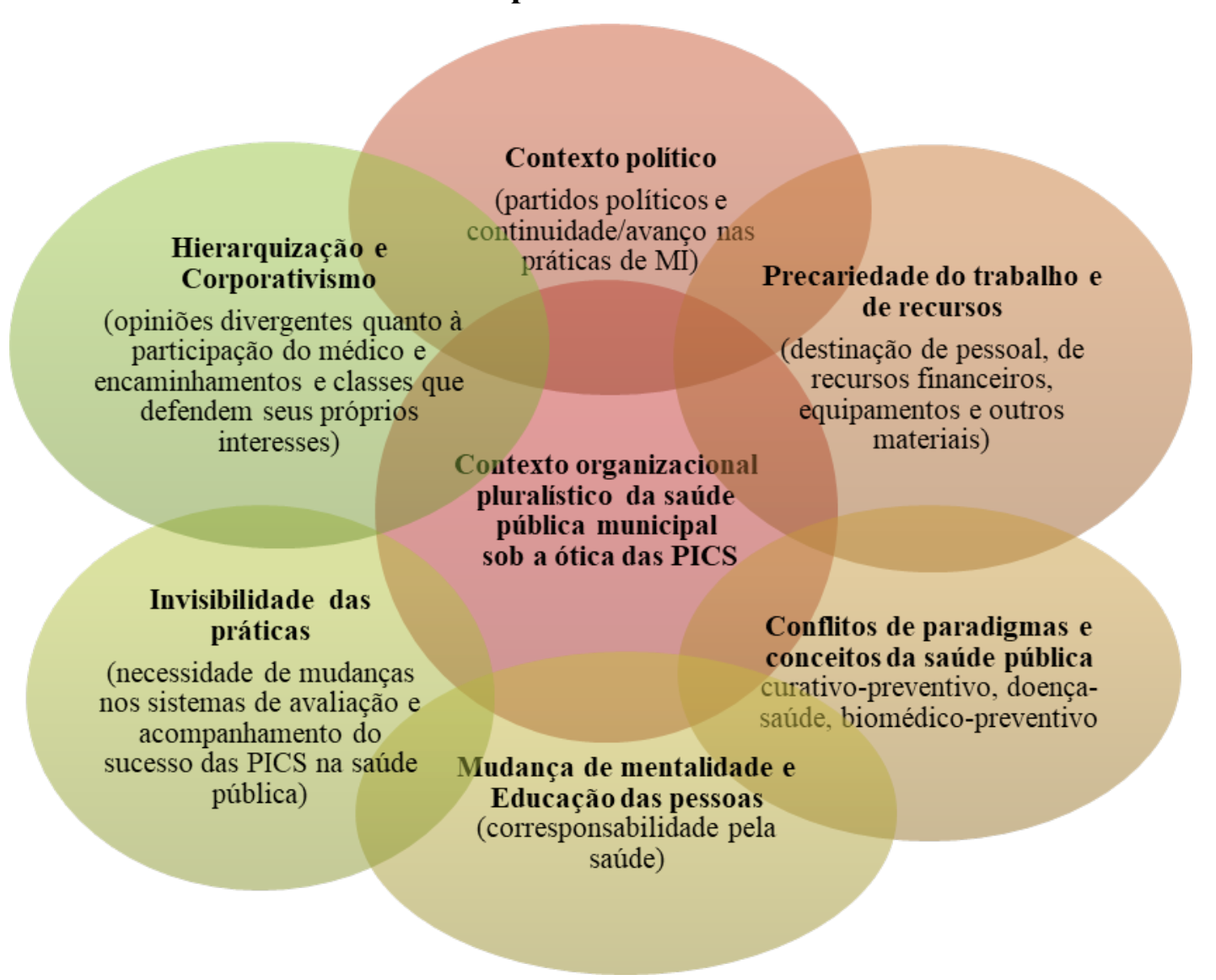

Fonte: elaborada pelas autoras.

A Figura 2 apresenta seis características do contexto organizacional das Unidades de Saúde pesquisadas que mostram um contexto pluralístico: diversos objetivos e interesses de diferentes grupos, que atuam dentro e fora/extra organização (JARZABKOWSKI; FENTON, 2006), a presença de múltiplos objetivos relacionados com a alocação de recursos que contemple ao tratamento biomédico e a MI, ainda que os recursos destinados sejam 
insuficientes para uma ampliação da oferta da MI. Estão presentes os processos de trabalho baseados no conhecimento e o poder difuso para a tomada de decisões (DENIS; LANGLEY; ROULEAU, 2007). A tensão relacional tem várias origens, mas sobressai a concepção da MI vista como cumprindo um papel social e econômico, pois visa, em princípio, evitar que as pessoas busquem tratamentos secundários, e a NGP que tende a priorizar a dimensão econômica na busca por desempenho quantificável e redução e custos.

O processo de inserção municipal das PIC caracterizou-se por intensa participação popular e associações interessadas na oferta desses serviços à população (pesquisa documental e entrevistas). No contexto organizacional pluralístico (JARZABKOWSKI; FENTON, 2006) da saúde pública, profissionais, usuários e reguladores possuem seus próprios interesses e influenciam o processo de inserção de novas políticas de saúde. E a inserção de uma nova prática, neste caso a MI, resulta de uma combinação de expertises social e material (GHERARDI, 2010).

Dentro do CRM, a gente entende o seguinte: aquilo que necessita de diagnóstico e proposta de tratamento tem que ter o envolvimento do médico. [...]. Eu não tenho absolutamente nada contra outras pessoas fazerem determinados tipos de acompanhamento e terapêuticas, mas quando você tem um diagnóstico, é necessária obrigatoriamente a participação do médico. [...]. Então, assim, sem ter o diagnóstico e sem ter o médico participando, o Conselho entende que essa medicina não tem como prosperar [...] (entrevista concedida por André, representante do CRM, 2016).

O entrevistado Jonas (Acupuntura) destaca a influência de fatores políticos/partidários (FERNANDES; MACHADO; ANSCHAU, 2009; LORENZETTI et al., 2014), dificuldades de comprovação científica das PIC e ainda o fator econômico envolvendo essas terapias. Estes fatores podem exercer influência positiva e/ou negativa na inserção de novas políticas na saúde pública, o entrevistado enfatiza a importância da regulamentação. A visão dicotômica preventivo-curativo e a falta de consenso gera a falta de padrões internacionais e de controle de qualidade, que podem levar à falta de compreensão de como determinadas práticas são estabelecidas (WHO, 2013).

Depois que eu passei a fazer acupuntura, eu tive a noção do resultado, porque eu passei quase dois anos fazendo fisioterapia funcional e não tive resultados esperados da forma que eu estou 
tendo agora (entrevista concedida pelo usuário acupuntura/malva, 2016).

A dicotomia preventivo-curativo, que esperava-se que estivesse superada, emerge nas falas dos entrevistados e gera tensão nas interações cotidianas dos envolvidos (WILSON; JARZABKOWSKI, 2004) com a inserção da MI nas Unidades de saúde pesquisadas e na reconfiguração da relação entre todos os envolvidos no processo, com a redistribuição do espaço e dos recursos, e também com o surgimento de novas identidades e a modificação de relações de poder dos envolvidos (NICOLINI, 2007).

Em relação ao interesse social pelas PIC, foi visto que o mesmo é crescente (pesquisa documental). A aprovação e o interesse das pessoas podem ser atribuídos aos resultados positivos que elas experimentam ao complementarem seus tratamentos com as PIC (entrevistas com usuários). A divulgação das PIC para a população é realizada principalmente dentro das unidades (mural) e pelos próprios usuários. Os médicos de outras unidades de saúde encaminham os pacientes para essas terapias nas unidades pesquisadas, contribuindo assim para a disseminação das PIC e também com a proposta de complementaridade dessas práticas.

\subsection{AS PRÁTICAS DE ORGANIZING}

Em relação aos valores associados à MI, os resultados mostraram semelhanças nas três unidades analisadas. A oferta dessas terapias pela rede pública de saúde é entendida por muitos profissionais como um "avanço", e até mesmo "um sonho" realizado. Os profissionais reconhecem a eficácia nessas terapias e argumentam em prol de sua ampliação e fortalecimento no município. Os valores dos usuários também mostram um entendimento positivo da oferta da MI pela rede pública de saúde: valorizam essa oferta porque entendem que as condições de obter acesso a esses serviços pelo setor privado é dispendiosa, valorizam o caráter complementar das PIC e valorizam os resultados positivos que ela proporciona. Esses valores convergem para o aspecto da acessibilidade aos serviços públicos e vai ao encontro de um princípio primordial do SUS: a equidade (VECINA NETO, 2012).

Em relação às formas de representar a MI, também há um entendimento comum dos profissionais atuantes nas unidades analisadas. Em suas falas, os entrevistados citam: "cuidado", "uma forma de prevenir doenças", "ver o paciente em sua totalidade" (RAKEL, 2012). Para os entrevistados, a MI não substitui a abordagem biomédica, ela é complementar. Porém, estes profissionais percebem que muitos dos profissionais da abordagem biomédica 
representam a MI como pouco eficaz. Ademais, a pressão, no âmbito da NGP, por produtividade e resultados quantificáveis (e de curto prazo), desafia a implantação de práticas com ênfase em aspectos sociopolíticos, psicológicos, emocionais e até mesmo espirituais, como ocorre com a MI.

Em relação às novas práticas adotadas, foi possível notar especificidades no cotidiano de trabalho quanto às rotinas organizacionais e à maneira de atender os pacientes. As consultas das PIC são mais longas, buscando o histórico do paciente. Esse contato prolongado gera percepções positivas: "é muito boa [a relação com a terapeuta], uma nova amiga que eu encontrei"5. E, "a consulta é diferente, perguntam mais, conversam mais, investigam"6. As mudanças no conteúdo e no tempo de consultas mostram que a MI caminha em direção oposta à redução do tempo das consultas em prol do produtivismo.

A pesquisa evidenciou que a prevalência da estrutura social das unidades está baseada no modelo biomédico, porém ela pode sofrer mudanças quando os profissionais assumem diferentes papéis na implantação das PIC. Nas três unidades analisadas, observou-se aspectos comuns nas rotinas das coordenações que realizam as atividades de acordo com as demandas diárias, sejam aquelas relacionadas a questões técnicas e de manutenção, não se restringindo à gestão. Assim, práticas de organizing e strategizing estão constantemente sendo feitas e refeitas, sendo reconcebidas (WHITTINGTON et al., 2006).

A área da Medicina Antroposófica (Unidade Malva), também apresentou uma particularidade: atividades de pesquisa e ensino, tema destacado em documentos de órgãos da saúde (WHO, 2013; UBERLÂNDIA, 2013a). A dinâmica nas relações não se restringe ao público interno das unidades. Tanto a representante do Conselho Municipal de Saúde quanto a representante da Comissão Consultiva das PIC desempenham um trabalho de interação constante nas unidades: "a função do Conselho é mais de parceria do que fiscalização, mas as melhorias são cobradas [...]. A gente faz as reuniões nas salas de espera da unidade [...] a gente tenta envolver a população o máximo possível"7. E, no âmbito "das PIC existe uma Comissão Consultiva, ela não tem poder de decidir, mas ela tem o poder de andar em todos os departamentos, ajudar, falar o que está precisando, cobrar da gestão". ${ }^{8}$

As interações no cotidiano de trabalho mostram divergências e tensão. Há funcionários que percebem a MI como sendo "boa", "tranquila" e "coesa", devido a fatores como contato cotidiano e facilidade de encaminhamentos para as terapias (MINAS GERAIS,

\footnotetext{
${ }^{5}$ Entrevista concedida pela usuária Reiki/Alecrim, 2016.

${ }^{6}$ Entrevista concedida pela usuária Acupuntura/Malva, 2016.

${ }^{7}$ Entrevista concedida por Ângela, Cms, 2016.

${ }^{8}$ Entrevista concedida por Kátia, Comissão Consultiva, 2016.
} 
2014). Porém, há aqueles que acreditam em uma interação "fraca". Essas definições estão relacionadas a pouca interação entre os profissionais, principalmente de áreas distintas, para tratar da MI, à falta de uma política de reuniões periódicas e à falta de conhecimento sobre as PIC por parte de muitos profissionais. O espectro de opiniões distintas dentro dos mesmos ambientes de trabalho pode estar relacionado às diferenças históricas e culturais que geram percepções destoantes (FENTON; LANGLEY, 2011), e mesmo concepções ideológicas sobre a destinação de recursos públicos e resultados na gestão pública (PAULA, 2007).

Em relação à disseminação das PIC, a comunicação ainda é reduzida. A frequência de reuniões é baixa, especificamente sobre as PIC. A Unidade Malva tem uma política mensal de reuniões, em que são discutidos pontos específicos dos atendimentos da unidade, esclarecimentos administrativos aos funcionários, assim como dificuldades enfrentadas pelas PIC (notas de campo). Entretanto, não são todos os profissionais que participam devido a outras atribuições. Esse fator pode ser uma das causas do baixo conhecimento dessas práticas entre os profissionais da rede e de algumas imagens negativas. As outras duas unidades analisadas, Camomila e Alecrim, realizam reuniões, porém não foi observada reunião para assuntos específicos das PIC.

\subsection{AS PRÁTICAS DE STRATEGIZING}

Em relação aos objetivos e às expectativas com a MI na rede pública, a maioria dos entrevistados argumenta a favor da ampliação do oferecimento das PIC. Os profissionais de saúde manifestam incerteza acerca do empenho político em direção à MI e frustração acerca das suas expectativas de expansão da MI na rede pública de saúde. Eles relatam que, embora regulamentadas em âmbito federal, as PIC dependem de políticas e do interesse local: seja sobre o que (conteúdo, atividades, equipamentos) e quando (em que ritmo) implementar. A demora e/ou não concretização de projetos como a farmácia popular, não são apenas resultado, mas também contribuem para a falta de conhecimento e preparo dos profissionais (ISCHKANIAN; PELICIONI, 2012), no que se refere a inserção das PIC.

Os profissionais de saúde falam da dificuldade nas condições de gestão para o atingimento de objetivos e a necessidade de superar a resistência de outros profissionais de saúde contrários à MI. A resistência às PIC pode ser explicada devido à incorporação de novas práticas que mudam as interações e transformam as relações de poder no campo da saúde e, também, por uma forte presença da ideologia gerencialista no campo da 
administração pública (PAULA, 2008), e diferentes concepções sobre governança (PECI; PIERANTI; RODRIGUES, 2008).

Em relação à avaliação sobre a destinação de recursos para MI, os gestores informaram que os recursos geralmente são obtidos por meio de edital e incorporados na Atenção Básica, ou seja, não é enviado especificamente para as PIC. Entretanto, devido às particularidades dessas práticas, inclusive a fitoterapia e a farmácia, Simone (Auriculoterapia) e Elisa (Reiki) acreditam que o orçamento e a disponibilização de recursos deveriam ser independentes. Quanto aos profissionais das PIC, foi quase unanimidade a falta de conhecimento sobre a distribuição de recursos e por isso não conseguiram avaliá-lo. Os profissionais Jonas (Acupuntura), Vânia (Medicina Antroposófica) e Rodrigo (Homeopatia) falaram da dificuldade de se conseguir uma estrutura adequada, gerando uma avaliação negativa sobre a destinação de recursos. A insuficiência de recursos e estrutura influencia as micro práticas de atores pressionados em seus contextos a colaborarem para a construção de um "governo preventivo" (PAULA, 2007), em meio à crise do Estado, transferência de práticas do setor privado para o setor público e pressão global de empresas privadas interessadas no campo da saúde (macro práticas).

Em relação ao entendimento sobre as novas práticas pela oferta da MI, nas três unidades analisadas, foi possível notar que os profissionais compreendem a proposta da MI, porém o diálogo sobre essas práticas não acontece da forma desejada. Na coordenação da Unidade Malva, foi observada uma prática distinta, que visa organizar e instruir os encaminhamentos feitos para essa unidade: elaboração de documentos informativos, como o "Guia de Encaminhamento" e a "Ficha de Encaminhamento", documentos cedidos por esta unidade. $\mathrm{O}$ primeiro contém notas técnicas sobre as terapias oferecidas pela rede. $\mathrm{O}$ segundo contém informações sobre o paciente. Essa prática reforça uma das diretrizes estratégicas da Lei n. 11.309, referida como "Elaboração de normas e manuais técnicos", contribuindo para o esclarecimento sobre as PIC (UBERLÂNDIA, 2013a).

Em relação aos resultados da inserção das PIC, é consenso entre profissionais e usuários das três unidades que o oferecimento dessas terapias na rede pública tem gerado resultados positivos, como a diminuição no uso de remédios; melhoria na qualidade de vida; diminuição de filas nos outros níveis de atendimento; e baixos custos de implantação dessas práticas. Entretanto, os profissionais entrevistados avaliam que existem fatores relacionados a uma gestão centralizada e com pequeno nível de autonomia (REZENDE, 2009), que dificultam a concretização de projetos (farmácia popular) e melhores resultados. Ademais, precisam ser superados desafios como: carência de profissionais e materiais; falta do 
entendimento do propósito das PIC; falta de capacitação; e influência de setores resistentes. Até por isso, quando perguntados sobre o futuro da MI no atendimento público de saúde, há consenso entre os entrevistados no sentido de esperar que ocorra uma expansão dos serviços, mas, ao mesmo tempo, a maioria reconhece uma incerteza nas possíveis mudanças políticas.

\subsection{MODOS DE ASSOCIAÇÃO ENTRE STRATEGIZING E ORGANIZING COM A} INSERÇÃO DAS PIC NO SUS

No contexto da saúde pública, as estratégias relativas às PIC, sejam elas relacionadas à inserção ou expansão, são amplamente definidas por meio de políticas públicas (PNPIC) ou por meio de instrumentos legais (Lei n. 11.309) (UBERLÂNDIA, 2013a). Esta pesquisa mostrou que a inserção dessas práticas no contexto organizacional pluralístico estudado gerou dois modos de associação entre strategizing e organizing.

Figura 3 - Contexto pluralístico e práticas de organizing e strategizing na inserção das

PIC

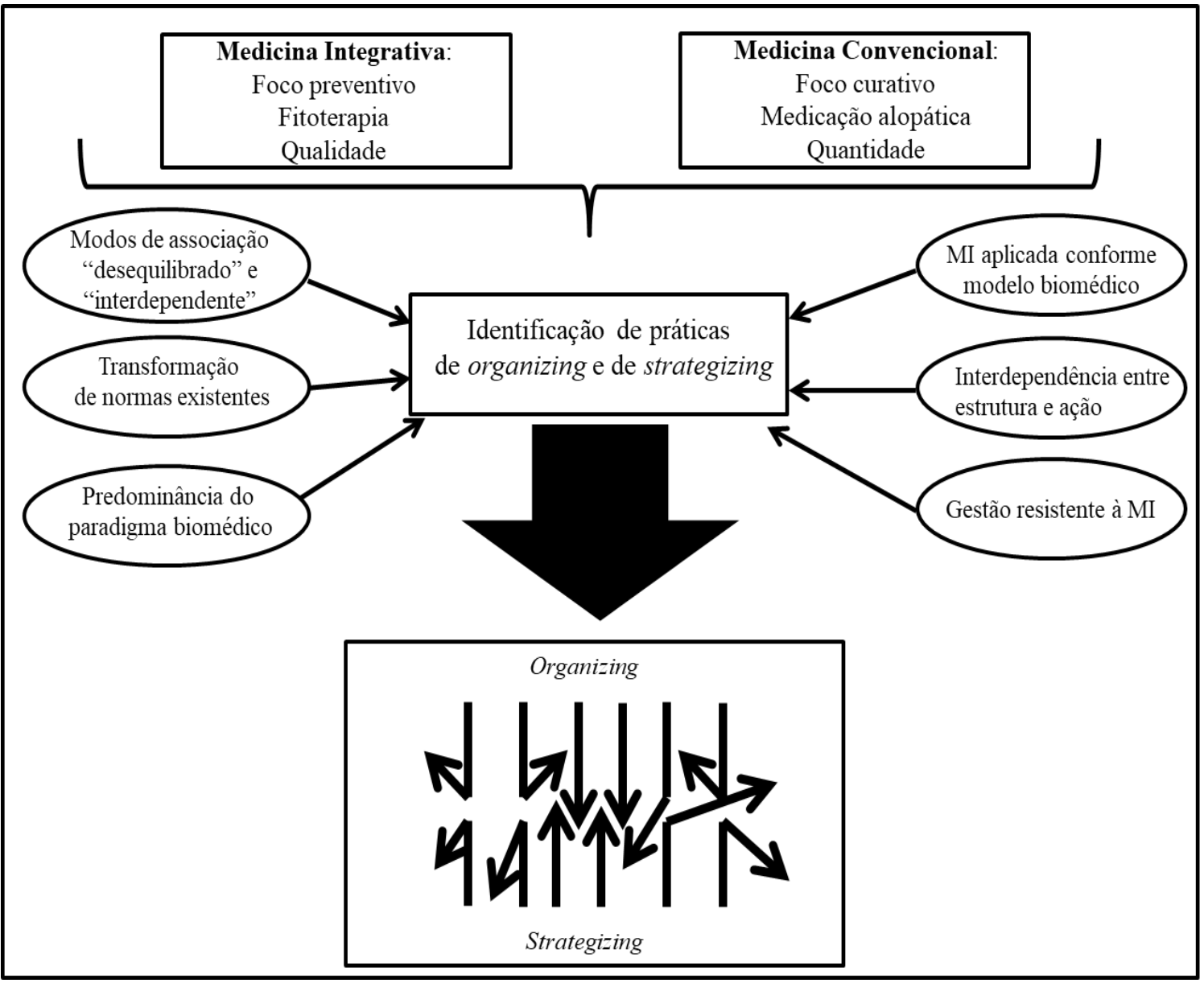

Fonte: elaborada pelas autoras. 
Na Figura 3, o contexto da saúde pública é representado pela pluralidade envolvendo características da MI e da Medicina Convencional, conforme representado nos dois retângulos superiores. Nesse contexto, foi possível identificar as práticas explicitadas de organizing e de strategizing, o que possibilitou o alcance dos principais resultados da presente pesquisa (representados pelos círculos).

O macro contexto da gestão pública, em que ocorrem as interações interorganizacionais, e as práticas dentro das unidades de saúde são co-construídas e modelam as práticas de organizing e de strategizing e os modos de associação dessas práticas (JARZABKOWSKI; FENTON, 2006). Na Figura 3, essas práticas são representadas pelas setas dentro do retângulo menor, micro contexto das unidades de saúde. Essas setas mostram uma relação de interdependência e também de desequilíbrio que ocorre entre as práticas de organizing e de strategizing. O contexto de atuação das unidades analisadas influencia as práticas dos atores atuantes em aspectos diversos.

Ao mudar suas estratégias sem considerar como as práticas existentes de organizing podem contrariar as metas e suas habilidades de alcançá-la, as organizações enfrentam um bloqueio das novas estratégias ou o impedimento de novas práticas de organizing. Essa característica é observada no modo de associação "desequilibrado". Como a PMPIC foi inserida sem considerar fatores como planejamento e capacitação, algumas práticas são identificadas no sentido de bloquear a inserção de novas estratégias, como as práticas de resistência (desconhecimento da gestão/necessidade de encaminhamento por outro profissional) e destinação geral e não específica de recursos. Também foram observadas e relatadas em entrevistas algumas práticas de organizing e de strategizing mutuamente ajustadas, criando práticas de organizing adaptadas às demandas dos diversos interesses de diferentes grupos organizacionais, levando à concepção do modo "interdependente". As práticas dinâmicas dos representantes de conselhos promovem uma articulação constante com a população; e o diálogo entre as associações que fizeram (e ainda fazem) parte do processo de inserção das PIC. Já as práticas inovadoras auxiliam a ampliação da MI.

Finalmente, observou-se a predominância do paradigma biomédico, no mesmo espaço em que ocorrem os esforços dos praticantes da estratégia e das práticas das instituições responsáveis pela implementação das PIC. Este cenário favorece as resistências por parte da gestão em aplicar estratégias relacionadas às "novas" práticas de saúde, uma vez que ainda não há consenso e conhecimentos amplamente difundidos sobre seus resultados, custos e benefícios para a população local. A pesquisa mostrou que as práticas de MI vêm sendo utilizada de acordo com os preceitos da medicina convencional, ou seja, como um tratamento 
após o usuário já apresentar doença/sintoma, e não em caráter preventivo conforme seus princípios.

\section{CONCLUSÕES}

Esta pesquisa analisou o modo como se configuram as práticas de strategizing e de organizing com inserção da MI no sistema público de saúde municipal, a partir da perspectiva da ECP. A análise das atividades no nível dos profissionais, usuários e outros praticantes (microssocial) mostrou a construção das micro práticas da MI situadas em um contexto mais amplo (macrossocial) da reforma do modelo de gestão da saúde pública (NGP).

Os resultados mostram que as práticas de strategizing e organizing estão cronicamente envolvidas na produção/reprodução de um contexto organizacional pluralístico de saúde pública municipal. Os olhares sobre os modos de configuração das práticas de strategizing e organizing mostram os praticantes fazendo uso de regras e recursos, conforme as normas disponíveis, mas também os mostram criando alternativas e transformando as regras e desenvolvendo novos recursos.

Em um contexto pluralístico, em que o paradigma predominante é o biomédico, todos os profissionais envolvidos com as PIC defendem a ideia de prevenção, clamando por mais investimentos em práticas de "Atenção Básica". A ideia da prevenção é vista como um avanço, que parte de uma gestão que prioriza a dimensão sociopolítica, a participação da população em políticas públicas de saúde e a promoção da cidadania. A ideia de um governo preventivo é parte dos princípios da NGP. Mas, este mesmo modelo de gestão dificulta a inserção da MI, ao priorizar resultados mais imediatos de desempenho e produtividade e promover a insuficiência de recursos para a MI como, por exemplo, a não implantação de uma farmácia popular que complementaria o atendimento já oferecido de práticas de MI. Tensões e dicotomias que se esperava estar superadas ainda persistem (por conveniência ou por falta de conhecimento) nas interações cotidianas entre uma população que busca tratamentos complementares de saúde e agentes de saúde e políticos municipais que recuam diante da possibilidade de avançar as práticas de MI por temer o aumento da procura por estas práticas. A maioria (resultado das entrevistas) das pessoas é encaminhada para as PIC já com alguma doença crônica, ou seja, as PIC têm sido utilizadas como uma forma de cura e não de promoção à saúde. 
Outro fato identificado, é que não se trata de substituição de paradigmas, tendo em vista o caráter complementar das PIC e a superação das dicotomias curativo-preventivo no campo da saúde pública. Em relação aos usuários, os resultados mostram o interesse e a valorização do tratamento com a MI. Entretanto, a maioria dos usuários soube do oferecimento das PIC por meio de outras unidades de saúde e pelo próprio encaminhamento por outros profíssionais (médicos, psicólogos). Há pouca divulgação dessas práticas, que ocorre por conta da insuficiência de recursos caso a demanda cresça. Novamente, a dimensão econômica compromete o avanço na dimensão sociopolítica da gestão pública.

A estratégia como uma prática social contribui com a análise da gestão da saúde pública ao oferecer conceitos como organizing e strategizing, contexto pluralístico organizacional, conflitos e tensão relacional, a inserção de novas práticas/tecnologias/conhecimento e as interações cotidianas de agentes e trabalhadores da saúde, políticos tomadores de decisão, a população e grupos organizados, representantes de associação de classe. O presente estudo não teve a pretensão de esgotar todas as práticas de organizing e strategizing do contexto de inserção das PIC. Esta pesquisa não considerou todos os atores envolvidos no contexto de atuação das unidades analisadas. O que deixa espaço para pesquisas futuras que contemplem a inclusão de outras unidades de saúde municipais, estaduais e nacionais, e a inclusão de profissionais que atuam como paradigma biomédico, construindo um diálogo baseado no pluralismo das práticas de MI e na promoção de cidadania-saúde.

\section{REFERÊNCIAS}

AROUCA. S. O dilema preventivista. Rio de Janeiro: Fiocruz, 2003.

BISPO, M. de S. Aprendizagem organizacional baseada no conceito de prática: contribuições de Silvia Gherardi. Revista de Administração Mackenzie (RAM), v. 14, n. 6, p. 132-161, 2013.

BARROS, N. F., SPADACIO, C.; COSTA, M. V. Trabalho interprofissional e as Práticas Integrativas e Complementares no contexto da Atenção Primária à Saúde: potenciais e desafios. Saúde em Debate, v. 42, n. especial 1, p. 163-173, 2018.

RASIL. Ministério da Saúde. Secretaria de Atenção à Saúde. Política Nacional de Práticas

Integrativas e Complementares no SUS. Brasília, 2006. Disponível em:

http://bvsms.saude.gov.br/bvs/publicacoes/pnpic.pdf. Acesso em: 30 jul. 2018. 
BRASIL. Ministério da Saúde. Secretaria de Atenção à Saúde. Relatório do $1^{\circ}$ Seminário Internacional de Práticas Integrativas e Complementares em Saúde - PNPIC. Brasília, 2009. Disponível em:

http://bvsms.saude.gov.br/bvs/publicacoes/seminario_praticas_integrativas_complementares_ saude.pdf. Acesso em: 14 fev. 2019.

BUSS, P.M. Uma introdução ao conceito de promoção da saúde. In: CZERESNIA, D.;

FREITAS, C. M. (Orgs.) Promoção da saúde: conceitos, reflexões e tendências. Rio de Janeiro: Fiocruz, 2009.

CARVAlHO, G. A saúde pública no Brasil. Estudos Avançados, v. 27, n. 78, p. 7-26, 2013. CASTRO, A. M. ET AL. (Orgs.). Curso de extensão para gestores do SUS em promoção da saúde. Organizadores. Brasília: CEAD/UNB, 2010. Disponível em:

http://portalarquivos2.saude.gov.br/images/pdf/2014/julho/15/livro-ead-promocao-da-saudeedicao-10.pdf. Acesso em: 14 fev. 2019.

COLVILLE, I. D.; MURPHY, A. J. Leadership as the Enabler of strategizing and organizing. Long Range Planning, v. 39, p. 663-677, 2006.

COSTA, R. P; MISOCZKY, M. C.; ABDALA, P. R. Z. Do dilema preventivista ao dilema promocionista: retomando a contribuição de Sérgio Arouca. Saúde em Debate, v. 42, n. 119, p. 990-1001, 2018.

DENIS, J.-L.; LANGLEY, A.; ROULEAU, L. Strategizing in pluralistic contexts: rethinking theoretical frames. Human Relations, v. 60, n. 1, p. 179-215, 2007.

DENZIN, N. K.; LINCOLN, Y. S. The Sage handbook of qualitative research. London: Sage Publications, 2005.

ESCOREL, S.; AROUCA, L. E. Democracia e participação: para além das dicotomias. Saúde em Debate, v. 40, n. especial, p. 39-48, 2016.

ESCRIVÃO JÚNIOR, A. A epidemiologia e o processo de assistência à saúde. In: VECINA NETO, G.; MALIK, A. M. Gestão em Saúde. Rio de Janeiro: Koogan, 2012.

FERNANDES, C. L. F.; MACHADO, R. Z.; ANSCHAU, G. O. Gerência de serviços de saúde: competências desenvolvidas e dificuldades encontradas na atenção básica. Ciência $\&$ Saúde Coletiva, v. 14, n. 1, p. 1541-1552, 2009.

FINKELMAN, J. Caminhos da saúde pública no Brasil. Rio de Janeiro: Fiocruz, 2002. FONTANELLA, F.; SPECK, F. P.; PIOVESAN, A. P.; KULKAMP, I. C. Conhecimento, acesso e aceitação das práticas integrativas e complementares em saúde por uma comunidade usuária do Sistema Único de Saúde na cidade de Tubarão/SC. Arquivos Catarinenses de Medicina, v. 36, n. 2, p. 69-74, 2007. 
GHERARDI, S. Practice? It's a Matter of Taste! Management Learning, v. 40, n. 5, p. 535$550,2009$.

GHERARDI, S. Telemedicine: a practice-based approach to technology. Human Relations, v. 63, n. 4 , p. 501-524, 2010.

GHERARDI, S. How to conduct a Practice-based Study. Cheltenham, UK/ Northamptom, MA, USA: 2012.

GHERARDI, S.; NICOLINI, S. Learning in a constellation of interconnected practices:

canon or dissoance? Journal of Management Studies, v. 39, n. 4, p. 419-436, 2002.

GRIX, J. Introducing students to the generic terminology of social research. Politics, v. 22, n. 3, p. 175-186, 2002.

ISCHKANIAN, P. C.; PELICIONI, M.C. F. Desafios das práticas integrativas e complementares no SUS visando à promoção da saúde. Revista Brasileira de Crescimento e Desenvolvimento Humano, v. 22, n. 1, p. 233-238, 2012.

JARZABKOWSKI, P. Strategy as practice: recursiveness, adaptation, and practices-in-use. Organization Studies, v.25, n. 4, p. 529-560, 2004.

JARZABKOWSKI, P. Strategy as practice: an activity-based approach. London: Sage Publications, 2005.

JARZABKOWSKI, P.; BALOGUN, J.; SEIDL, D. Strategizing: the challenges of a practice perspective. Human Relations, v. 60, n. 1, p. 5-27, 2007.

JARZABKOWSKI, P.; FENTON, E. Strategizing and organizing in pluralistic contexts.

Long Range Planning, v. 39, p. 631-648, 2006.

JARZABKOWSKI, P.; SPEE, A. P.; SMETS, M. Material artifacts: practices for doing strategy with stuff. European Management Journal, v. 31, n. 1, p. 41-54, 2013.

LIMA, K. M. C. V.; SILVA, K.L.; TESSER, C. D. Práticas integrativas e complementares e relação com promoção da saúde: experiência de um serviço municipal de saúde. Interface:

Comunicação, Saúde, Educação, v. 18, n. 49, p. 261-272, 2014.

LOCH-NECKEL, G.; CARMIGNAN, F.; CREPALDI, M. A. A homeopatia no SUS na perspectiva de estudantes da área da saúde. Revista Brasileira de Educação Médica, v. 34, n. 1, p. 82-90, 2010.

LODGE, M.; GILL, D.Toward a new era of administration reform? The myth of post-NPM in New Zealand. Governance: An International Journal of Policy, Administration, and Institutions, v. 24, n. 1, p. 141-166, 2011. 
LORENZETTI, J.; LANZONI, G. M. M.; ASSUITI, L. F. C.; PIRES, D. E. P.; RAMOS, F. R. S. Gestão em saúde no Brasil: diálogo com gestores públicos e privados. Texto em Contexto Enfermagem, v. 23, n. 2, p. 417-425, 2014.

MACHADO; D. C.; CZERMAINSKI, S. B. C.; LOPES, E. C. Percepções de coordenadores de unidades de saúde sobre a fitoterapia e outras práticas integrativas e complementares.

Saúde e Debate, v. 36, n. 95, p. 615-623, 2012.

MANIATOPOULOS, G.; PROCTER, R.; LLEWELLYN, S.; HARVEY, G.; BOYD, A. Moving beyond local practice: reconfiguring the adoption of a breast cancer diagnostic technology. Social Science \& Medicine, v. 131, p. 98-106, 2015.

MENDES, A.; LEITE, M. G.; MARQUES, R. M. Discutindo uma metodologia para a alocação equitativa de recursos federais para o Sistema Único de Saúde. Saúde e Sociedade, v. 20, n.3, p. 17-25, 2011.

MINAS GERAIS. Caderno de práticas integrativas e complementares no SUS/MG. Belo Horizonte: ESP, 2014.

MINAYO, M. C. S.; COIMBRA JR, C. E. Críticas e atuantes: ciências sociais e humanas em saúde na América Latina [online]. Rio de Janeiro: Editora Fiocruz, 2005. Disponível em: https://static.scielo.org/scielobooks/w5p4j/pdf/minayo-9788575413920.pdf. Acesso em: 05 mar. 2019.

NAGAI, S. C.; QUEIROZ, M. S. Medicina complementar e alternativa na rede básica de serviços de saúde: uma aproximação qualitativa. Ciência e Saúde Coletiva, v. 16, n. 3, p. 1793-1800, 2011.

NICOLINI, D. Stretching out and expanding work practices in time and space: the case of telemedicine. Human Relations, v. 60, n. 6, p. 889-920, 2007.

NICOLINI, D. Zooming in and out: studying practices by switching theoretical lenses and trailing connections. Organization Studies, v. 30, n. 12, p. 1391-1418, 2009.

NICOLINI, D. Practice Theory, work \& Organization. United Kingdom: Oxford University Press, 2012.

NORONHA, J. C.; LIMA, L. D.; MACHADO, C. V. O Sistema Único de Saúde - SUS. In: GIOVANELLA, L.; ESCOREL, S.; LOBATO, L. V. C.; NORONHA, J. C.; CARVALHO, A. I. (Orgs.) Políticas e sistema de saúde no Brasil. Rio de Janeiro: Fiocruz, 2008. OMS. Official Records of the World Health Organization $n^{\circ} 2,1948$. Disponível em: http://apps.who.int/iris/bitstream/10665/85573/1/Official_record2_eng.pdf. Acesso em: 14 fev. 2019. 
PAIM, J.; TRAVASSOS, C.; ALMEIDA, C.; BAHIA, L.; MACINKO, J. O sistema de saúde brasileiro. Saúde no Brasil, v. 377, n. 9.779, 2011.

PATTON, M. Q. Qualitative evaluation and research methods. London: SAGE Publications, 1990.

PAULA, A. P. P. Por uma nova gestão pública. Rio de Janeiro: Editora FGV, 2007.

PECI, A.; PIERANTI, O. P.; RODRIGUES, S. Governança e New Public Management: convergências e contradições no contexto brasileiro. $\mathbf{O} \& \mathbf{S}$, v. 15, n. 46, p. 39-55, 2008. PEREIRA, C. F.; VILLELA, W. V. Acupuntura na rede pública de saúde: uma análise sobre a organização e funcionamento na unidade de referência em Uberlândia-MG. SUS: Mosaico de Inclusões, v. 13, n. 2, p. 156-161, 2008.

RAKEL, D. Integrative medicine. New York: Elsevier, 2012.

REZENDE, F. C. Desafios gerenciais para a reconfiguração da administração burocrática brasileira. Sociologias, ano 11, n. 21, p. 344-365, 2009.

RICHARDSON, R. J. Pesquisa social: métodos e técnicas. São Paulo: Atlas, 2014. RIVKIN, J. W.; SIGGELKOW, N. Organizing to strategize in the face of interactions: preventing premature lock-in. Long Range Planning, v. 39, p. 591-614, 2006.

SANO, H.; ABRUCIO, F. L. Promessas e resultados da Nova Gestão Pública no Brasil: o caso das organizações sociais de saúde em São Paulo. Revista de Administração de Empresas, v. 48, n. 3, p.64-80, 2008.

SANTOS, L. M.; FRANCISCO, J. R. S.; GONÇALVES, M. A. Controle na alocação de recursos na saúde pública: uma análise nas microrregiões do sudeste brasileiro.

Administração Pública e Gestão Social, v. 8, n. 2, p. 119-130, 2016.

SCLIAR, M. História do conceito de saúde. Physis: Revista de Saúde Coletiva, v. 17, n. 1, p. 29-41, 2007.

SEGRE, M.; FERRAZ, F. C. O conceito de saúde. Revista de Saúde Pública, v. 31, n. 5, p. 538-542, 1997.

TESSER, C. D.; SOUSA, I. M. C.; NASCIMENTO, M. C. Práticas Integrativas e Complementares na Atenção Primária à Saúde brasileira. Saúde em Debate, v. 42, n. especial 1, p. 174-188, 2018.

VAARA, E.; WHITTINGTON, R. Strategy as practice: taking social practices seriously. Academy of Management Annals, v. 6, n. 1, p.285-336, 2012.

VECINA NETO, G.A evolução da assistência à saúde no mundo e no Brasil até o SUS. In:

VECINA NETO, G.; MALIK, A. M. Gestão em Saúde. Rio de Janeiro: Koogan, 2012. 
WHITTINGTON, R. The work of strategizing and organizing: for a practice perspective. Strategic Organization. v. 1, n. 1, p. 117-125, 2003.

WHITTINGTON, R. Estratégia após o modernismo: recuperando a prática. Revista de Administração de Empresas, v. 44, n. 4, n. p., 2004.

WHITTINGTON, R. Completing the practice turn in strategy research. Organization Studies, v. 27, n. 5, p. 613-634, 2006.

WHITTINGTON, R.; MELIN, L. The Challenge of organizing/strategizing. In:

PITTIGREW, A. et al. Innovative forms of organizing (p. 35-48). Sage Publications, 2003.

WHITTINGTON, R.; MOLlOY, E.; MAYER, M.; SMITH, A. Practices of

strategising/organising: broadening strategy work and skills. Long Range Planning, v. 39, p. 615-629, 2006.

WHO. Traditional Medicine Strategy2014-2023. 2013. Disponível em:

http://apps.who.int/iris/bitstream/10665/92455/1/9789241506090_eng.pdf?ua=1. Acesso em: 10 set. 2017.

WILSON, D. C.; JARZABKOWSKI, P. Thinking and acting strategically: new challenges for interrogating strategy. European Management Review, v. 1, n. 1, p. 14-20, 2004. 